\title{
Dual Star Induction Motor Drive: Modelling, Supplying and Control
}

\author{
${ }^{1} \mathrm{H}$. Khouidmi, ${ }^{2} \mathrm{~A}$. Massoum and ${ }^{2} \mathrm{~A}$. Meroufel \\ ${ }^{1}$ Department of Electrical Engineering, Feculty of Engineering, \\ Hassiba Ben Bouali University, Chlef, Algeria \\ ${ }^{2}$ Department of Electrical Engineering, Feculty of Engineering, \\ Djillali Liabes University, Sidi Bel-Abbes, Algeria
}

\begin{abstract}
This study deals with an overview of principles space vector control for dual star induction motor and 5 level inverter with Space Vector Pulse Width Modulation (SVPWM) technique. A dual star induction motor rated at $4.5 \mathrm{~kW}, 220 \mathrm{~V}, 1$ pole pair, $50 \mathrm{~Hz}$ is modeled in vectorized form in the stator frame. The voltage waveforms are generated by the space vector modulation technique and the control method presented is indirect rotor Field Oriented Control (FOC) with stator currents regulation. The trajectories tracking, robustness to parameters variations and disturbance rejection are successfully achieved using PI controller.
\end{abstract}

Key words: Modelling, Dual Star Induction Machine (DSIM), Space Vector Pulse Width Modulation (SVPWM), Field Oriented Control (FOC), modeled, disturbance, modulation

\section{INTRODUCTION}

The multi-phase drives offer the improvement of the system reliability which is of great interest in specialized applications such as electric/hybrid vehicles or aerospace applications. Consequently if one phase is lost the drive continues operating, although at different rating values. This induction machine has 2 sets of 3-phase windings which are spatially phase shifted by 30 electrical degrees with isolated neutrals (Bojoi et al., 2005; Munoz and Lipo, 2000). The dual 3-phase induction machine is a 6 dimensional system. Therefore, modelling and control of this machine in the original reference frame would be very difficult. Because of this reason, the Park transformation is necessary. For analysis and control purposes, the

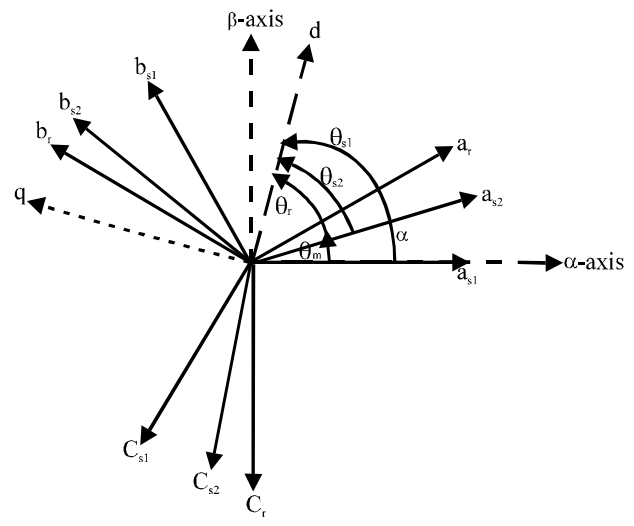

Fig. 1: DSIM axis presentation original 6 dimensional machine system can be decomposed into 2 dimensional orthogonal subspaces $\mathrm{dq}$ or $\alpha, \beta$-axis as shown in Fig. 1 .

\section{MATERIALS AND METHODS}

The model of the DSIM drive will be described in stator field coordinates. This system of equations is nonlinear. The indices $\mathrm{r}, \mathrm{s} 1$ and $\mathrm{s} 2$ mean rotor, stator 1 and stator 2, respectively. The Park model in set of equation of state is presented below (Munoz and Lipo, 2000; Gregor et al., 2008; Hadiouche, 2001).

\section{Electrical part:}

$$
\begin{aligned}
& {\left[\mathrm{V}_{\mathrm{dqs} 1}\right]=\mathrm{R}_{\mathrm{s} 1} \cdot\left[\mathrm{I}_{\mathrm{dqs} 1}\right]+\frac{\mathrm{d}}{\mathrm{dt}}\left[\Phi_{\mathrm{dq} 1}\right]-\omega_{\mathrm{s}} \cdot\left[\Phi_{\mathrm{qds} 1}\right]} \\
& {\left[\mathrm{V}_{\mathrm{dqs} 2}\right]=\mathrm{R}_{\mathrm{s} 2} \cdot\left[\mathrm{I}_{\mathrm{dqs} 2}\right]+\frac{\mathrm{d}}{\mathrm{dt}}\left[\Phi_{\mathrm{dq} 2}\right]-\omega_{\mathrm{s}} \cdot\left[\Phi_{\mathrm{qds} 2}\right]} \\
& {\left[\mathrm{V}_{\mathrm{dqr}}\right]=\mathrm{R}_{\mathrm{r}} \cdot\left[\mathrm{I}_{\mathrm{dqr}}\right]+\frac{\mathrm{d}}{\mathrm{dt}}\left[\Phi_{\mathrm{dqr}}\right]-\left(\omega_{\mathrm{s}}-\omega_{\mathrm{r}}\right) \cdot\left[\Phi_{\mathrm{qdr}}\right]}
\end{aligned}
$$

We will eliminate, the use of currents in the model and we will use the flux instead. The connection between these 2 variables is as follows:

$$
\begin{aligned}
& {\left[\Phi_{\mathrm{dqs} 12}\right]=\mathrm{L}_{\mathrm{s} 12}\left[\mathrm{I}_{\mathrm{dqs} 12}\right]+\mathrm{L}_{\mathrm{m}}\left(\mathrm{I}_{\mathrm{dqs} 1}+\mathrm{I}_{\mathrm{dqs} 1}+\mathrm{I}_{\mathrm{dqr}}\right)} \\
& {\left[\Phi_{\mathrm{dqr}}\right]=\mathrm{L}_{\mathrm{r}}\left[\mathrm{I}_{\mathrm{dqr}}\right]+\mathrm{L}_{\mathrm{m}}\left(\mathrm{I}_{\mathrm{dqs} 1}+\mathrm{I}_{\mathrm{dqs} 2}+\mathrm{I}_{\mathrm{dqr}}\right)}
\end{aligned}
$$

and state equation between flux and input voltage are:

Corresponding Author: H. Khouidmi, No 7 Vsa el, Attaf Ain Defla 44305, Algeria 


$$
\frac{\mathrm{d}}{\mathrm{dt}}[\Phi]=[\mathrm{A}] \cdot[\Phi]+[\mathrm{B}] \cdot[\mathrm{V}]
$$

Where:

$$
[\Phi]=\left[\begin{array}{c}
\Phi_{\mathrm{dqs} 1} \\
\Phi_{\mathrm{dq} 22} \\
\Phi_{\mathrm{dqr}}
\end{array}\right],[\mathrm{V}]=\left[\begin{array}{c}
\mathrm{V}_{\mathrm{dqs} 1} \\
\mathrm{~V}_{\mathrm{dqs} 2} \\
\mathrm{~V}_{\mathrm{dqr}}
\end{array}\right]
$$

The equation of flux is:

$$
\left[\Phi_{\mathrm{dqm}}\right]=\mathrm{L}_{\mathrm{m}}\left(\mathrm{I}_{\mathrm{dqs} 1}+\mathrm{I}_{\mathrm{dqs} 2}+\mathrm{I}_{\mathrm{dqr}}\right)
$$

or;

$$
\left[\Phi_{\mathrm{dqm}}\right]=\mathrm{L}_{\mathrm{a}} \cdot\left(\frac{\Phi_{\mathrm{dq} s 1}}{\mathrm{~L}_{\mathrm{s} 1}}+\frac{\Phi_{\mathrm{dq} 22}}{\mathrm{~L}_{\mathrm{s} 2}}+\frac{\Phi_{\mathrm{dq}}}{\mathrm{L}_{\mathrm{r}}}\right)
$$

Where:

$$
\mathrm{L}_{\mathrm{a}}=\frac{1}{\frac{1}{\mathrm{~L}_{\mathrm{m}}}+\frac{1}{\mathrm{~L}_{\mathrm{s} 1}}+\frac{1}{\mathrm{~L}_{\mathrm{s} 2}}+\frac{1}{\mathrm{~L}_{\mathrm{r}}}}
$$

The state matrix A and vector $\mathrm{B}$ in the $\mathrm{d}-\mathrm{q}$ axis are:

$$
\begin{gathered}
{[A]=\left[\begin{array}{cccccc}
a_{11} & a_{12} & a_{13} & 0 & a_{15} & 0 \\
a_{21} & a_{22} & 0 & a_{24} & a_{25} & 0 \\
a_{31} & 0 & a_{33} & a_{34} & 0 & a_{36} \\
0 & a_{42} & a_{43} & a_{44} & 0 & a_{46} \\
a_{51} & a_{52} & 0 & 0 & a_{55} & a_{56} \\
0 & 0 & a_{63} & a_{64} & a_{65} & a_{66}
\end{array}\right]} \\
{[B]=\left[\begin{array}{cccc}
1 & 0 & 0 & 0 \\
0 & 1 & 0 & 0 \\
0 & 0 & 1 & 0 \\
0 & 0 & 0 & 1 \\
0 & 0 & 0 & 0 \\
0 & 0 & 0 & 0
\end{array}\right]}
\end{gathered}
$$

Where:

$$
\begin{gathered}
\mathrm{a}_{11}=\mathrm{a}_{33}=\frac{\mathrm{L}_{\mathrm{a}}}{\mathrm{T}_{\mathrm{s} 1} \mathrm{~L}_{\mathrm{s} 1}}-\frac{1}{\mathrm{~T}_{\mathrm{s} 1}} \\
\mathrm{a}_{12}=\mathrm{a}_{24}=-\mathrm{a}_{31}=-\mathrm{a}_{42}=\omega_{\mathrm{s}}, \mathrm{a}_{15}=\mathrm{a}_{35}=\frac{\mathrm{L}_{\mathrm{a}}}{\mathrm{T}_{\mathrm{s} 1} \mathrm{~L}_{\mathrm{r}}} \\
\mathrm{a}_{21}=\mathrm{a}_{43}=\frac{\mathrm{L}_{\mathrm{a}}}{\mathrm{T}_{\mathrm{s} 2} \mathrm{~L}_{\mathrm{s} 1}}, \mathrm{a}_{22}=\mathrm{a}_{44}=\frac{\mathrm{L}_{\mathrm{a}}}{\mathrm{T}_{\mathrm{s} 2} \mathrm{~L}_{\mathrm{s} 2}}-\frac{1}{\mathrm{~T}_{\mathrm{s} 2}} \\
\mathrm{a}_{25}=\mathrm{a}_{46}=\frac{\mathrm{L}_{\mathrm{a}}}{\mathrm{T}_{\mathrm{s} 2} \mathrm{~L}_{\mathrm{r}}}, \mathrm{a}_{51}=\mathrm{a}_{63}=\frac{\mathrm{L}_{\mathrm{a}}}{\mathrm{T}_{\mathrm{s} 1} \mathrm{~L}_{\mathrm{r}}}
\end{gathered}
$$

$$
\mathrm{a}_{52}=\mathrm{a}_{64}=\frac{\mathrm{L}_{\mathrm{a}}}{\mathrm{T}_{\mathrm{s} 2} \mathrm{~L}_{\mathrm{r}}}, \mathrm{a}_{55}=\mathrm{a}_{66}=\frac{\mathrm{L}_{\mathrm{a}}}{\mathrm{T}_{\mathrm{r}} \mathrm{L}_{\mathrm{r}}}-\frac{1}{\mathrm{~T}_{\mathrm{r}}}
$$

$$
a_{56}=-a_{65}=\omega_{r}, T_{s}=\frac{L_{s}}{R_{s}}, T_{r}=\frac{L_{r}}{R_{r}}
$$

and;

$$
\omega_{\mathrm{r}}=\omega_{\mathrm{s}}-\omega_{\mathrm{m}}
$$

Mechanical parts: The mechanical equation is:

$$
\mathrm{J} \frac{\mathrm{d} \Omega_{\mathrm{m}}}{\mathrm{dt}}=\mathrm{T}_{\mathrm{e}}-\mathrm{T}_{\mathrm{m}}-\mathrm{K}_{\mathrm{f}} \cdot \Omega_{\mathrm{m}}
$$

The equation of the electromagnetic torque is:

$$
\mathrm{T}_{e}=\mathrm{p} \frac{\mathrm{L}_{\mathrm{m}}}{\mathrm{L}_{\mathrm{m}}+\mathrm{L}_{\mathrm{r}}}\left[\left(\mathrm{I}_{\mathrm{qs} 1}+\mathrm{I}_{\mathrm{qs} 2}\right) \cdot \Phi_{\mathrm{dr}}-\left(\mathrm{I}_{\mathrm{ds} 1}+\mathrm{I}_{\mathrm{ds} 2}\right) . \Phi_{\mathrm{qr}}\right](1
$$

Five-level voltage source inverter modelling: The structure of a typical 5-evel Voltage Source Inverter (VSI) of diode-clamped that uses IGBT devices is shown in Fig. 2.

The higher number of levels provides the advantages of higher power rating and lower output armonics (Bose, 2004; Menzies et al., 1994). The 24 switches can be power BJT, GTO or IGBT, the on/off sequence of all these devices must respect two conditions; three of the switches must always be on and three always off; the upper and the lower switches of same leg are driven with two complementary pulsed signals. In this way, no vertical conduction is possible, providing care is taken to ensure that there is no overlap in the power switch transitions.

A 5-level inverter has $5^{3}=125$ switching states, 8 switching devices (Table 1) and 6 clamping diodes for each phase leg and $4 \mathrm{DC}$-side capacitors. In general an $\mathrm{N}$-level inverter requires $2(\mathrm{~N}-1)$ switching devices and $2(\mathrm{~N}-2)$ clamping diodes for each phase leg and (N-1) DC-side capacitors where each switching device shares $\mathrm{V}_{\mathrm{d}} /(\mathrm{N}-1)$ voltage. It produces $\mathrm{N}-$ level phase voltage and $2 \mathrm{~N}-1$ level line voltage waves and $\mathrm{N}^{3}-(\mathrm{N}-1)^{3}$ voltage space vectors and $6^{(\mathrm{N}-1)}$ number of triangle (Yu and Figoli, 1998) (Fig. 3).

\begin{tabular}{llllllllll}
\multicolumn{7}{l}{ Table 1: Switching states of a phase groupe for a 5-level inverter } \\
$\begin{array}{lllllllll}\text { Switching } \\
\text { states }\end{array}$ & $\mathrm{S} 1$ & $\mathrm{~S} 2$ & $\mathrm{~S} 3$ & $\mathrm{~S} 4$ & $\mathrm{~S} 5$ & $\mathrm{~S} 6$ & $\mathrm{~S} 7$ & $\mathrm{~S} 8$ & $\mathrm{~V}_{\mathrm{N}}$ \\
\hline 4 & on & on & on & on & off & off & off & off & $\mathrm{V}_{\mathrm{dc}}$ \\
3 & off & on & on & on & on & off & off & off & $3 \mathrm{~V}_{\mathrm{dc}} / 4$ \\
2 & off & off & on & on & on & on & off & off & $\mathrm{V}_{\mathrm{dc}} / 2$ \\
1 & off & off & off & on & on & on & on & off & $\mathrm{V}_{\mathrm{dc}}$. 4 \\
0 & off & off & off & off & on & on & on & on & 0 \\
\hline
\end{tabular}




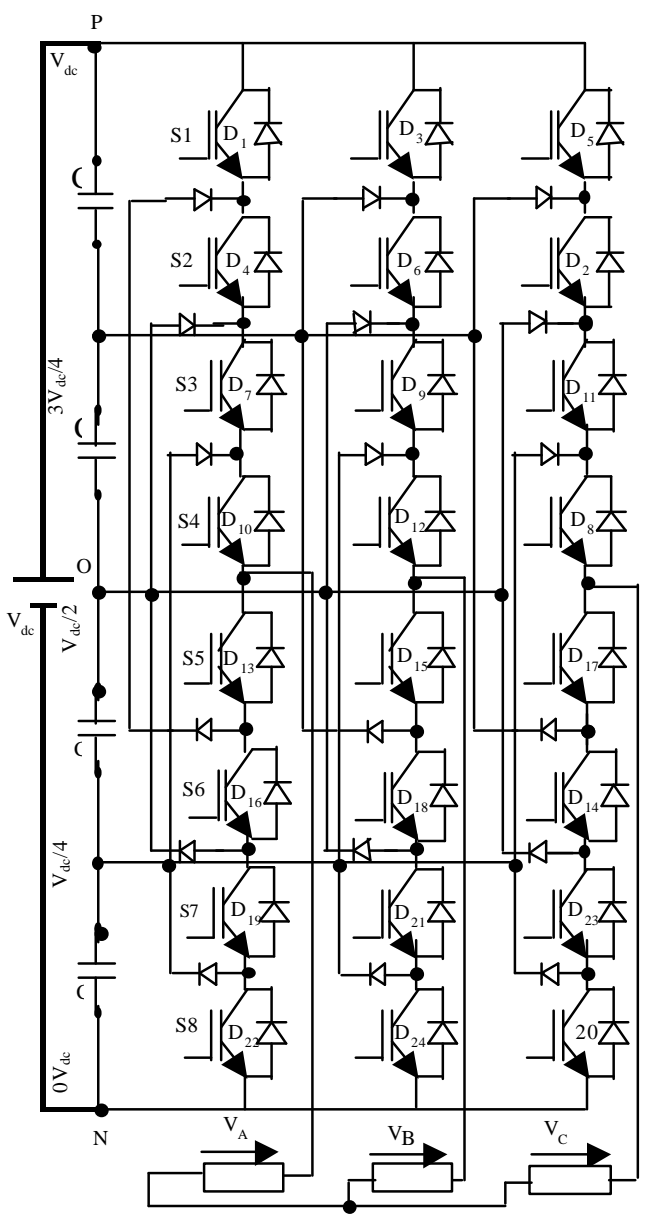

Fig. 2: Five-level 3-phase power inverter

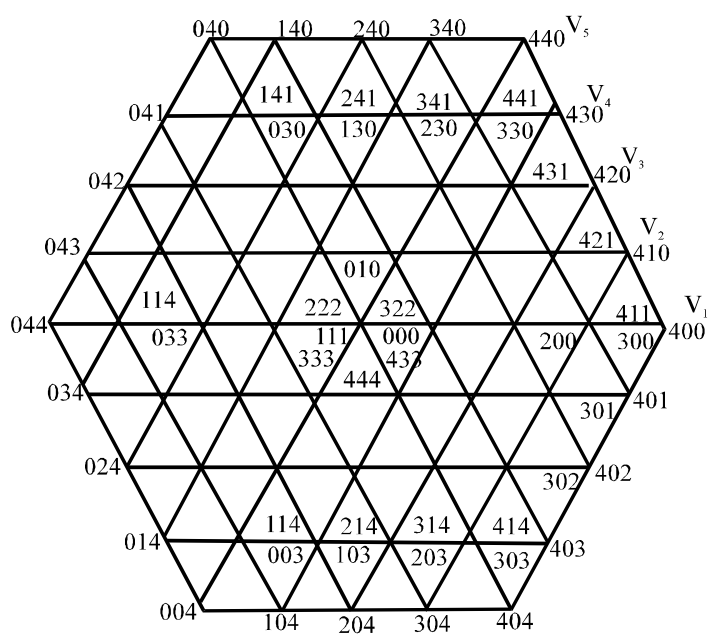

Fig. 3: Switching sequence for each sector for SVPWM

Space Vector Pulse Width Modulation technique (SVPWM): Space vector PWM refers to a special switching sequence of the upper 3 power switches of a 6-phase power inverter. It has been shown to generate less harmonic distortion in the output voltages applied to the phases of an DSIM motor and provides more efficient use of supply voltage in comparison with direct sinusoidal modulation technique (Hadiouche et al., 2003; Van der Broeck et al., 1988; Zhao and Lipo, 1995). The objective of space vector PWM technique is to approximate the reference voltage vector $\mathrm{V}$ by a combination of the 8 switching patterns. Equation 12 means for every PWM period, the desired reference voltage $\mathrm{V}$ can be approximated by having the power 2 level inverter in switching pattern $\mathrm{V}_{\mathrm{x}}, \mathrm{V}_{\mathrm{x}+15}$ and origin $\mathrm{O}$ (000) or (111) for $T_{1}, T_{2}$ and $T_{0}$ duration of time, respectively:

$$
\mathrm{T}_{\mathrm{pwm}} \cdot \mathrm{V}=\mathrm{T}_{1} \cdot \mathrm{V}_{\mathrm{x}}+\mathrm{T}_{2} \mathrm{~V}_{\mathrm{x}+15}+\mathrm{T}_{0}\left(\mathrm{O}_{000} \text { or } \mathrm{O}_{111}\right)
$$

The envelope of the hexagonal formed by the basic space vectors in Fig. 3 shows the angle between any adjacent two non-zero vectors is $15^{\circ}$ the zero vectors are at the origin and apply zero voltage to a motor (Hadiouche et al., 2003). The either vectors are called the basic space vectors and are denoted by $V_{0}, V_{15}, V_{30}, V_{45}$, $\mathrm{V}_{60}, \mathrm{~V}_{75}, \mathrm{~V}_{90}, \mathrm{~V}_{105}, \mathrm{~V}_{120}, \mathrm{~V}_{135}, \mathrm{~V}_{150}, \mathrm{~V}_{165}, \mathrm{~V}_{180}, \mathrm{~V}_{195}, \mathrm{~V}_{210}, \mathrm{~V}_{225}$, $\mathrm{V}_{240}, \mathrm{~V}_{2550}, \mathrm{~V}_{270}, \mathrm{~V}_{285}, \mathrm{~V}_{300}, \mathrm{O}_{000}$ and $\mathrm{O}_{111}$. The hexagonal is the locus of maximum $\mathrm{V}$ therefore, the magnitude of $\mathrm{V}$ must be limited to the shortest radius of this envelope when $\mathrm{V}$ is a rotating vector. This given a maximum magnitude of $\mathrm{V}_{\mathrm{dc}} / \sqrt{2}$ for $\mathrm{V}$. As shown in Fig. 3, the maximum rms values of the fundamental line to line and line to neutral output voltage are $\mathrm{v}_{\mathrm{dc}} / \sqrt{2}$ and $\mathrm{v}_{\mathrm{dc}} / \sqrt{6}$ which is $2 / \sqrt{3}$ times higher than what a sinusoidal PWM technique can generate. The resulting wave forms are a times-average version of PWM switching signals and show clearly the fundamental frequency at $\omega_{s}$ and the $3 r d$ harmonic at $3 \omega_{\mathrm{s}}$ which is inherently generated by the space vector strategy. As expected the three wave forms are spaced $120^{\circ} \mathrm{C}$ apart (Fig. 4). Figure $5 \mathrm{a}, \mathrm{b}$ shows the simulation results of the 5-level inverter for parameters modulations of PWM technique: modulation index $\mathrm{m}=0.8$, switching intervals $\mathrm{r}=24$ and switching frequency $\mathrm{f}_{\mathrm{sw}}=1200 \mathrm{~Hz}$. Figure $6 \mathrm{a}, \mathrm{b}$ shows the voltage harmonics in the phase, the simulation results show clearly low harmonic components.

Field oriented control of DSIM: The field oriented control based on projections which transform a 3-phase time and speed dependent system into a two co-ordinate time invariant system. These projections lead to a structure similar to that of a DC machine control by eliminating the rotor currents, Eq. 13 and 14 can be derived relating rotor fluxes with stator currents (Bojoi et al., 2003; 


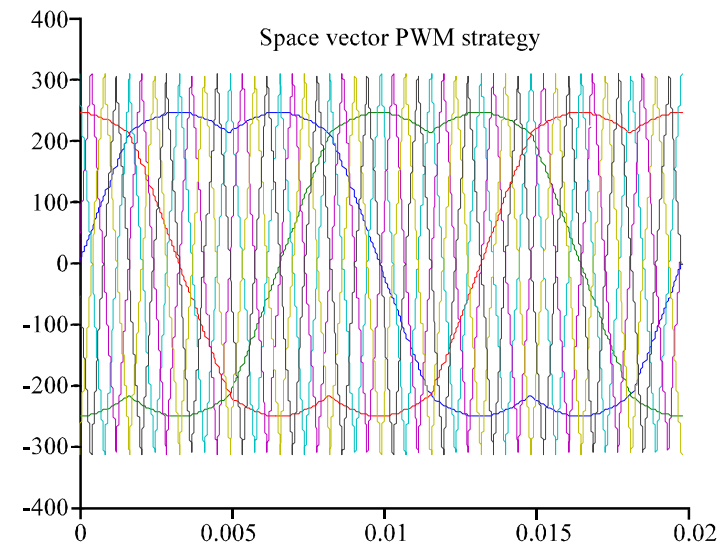

Fig. 4: The wave form of space vector PWM output
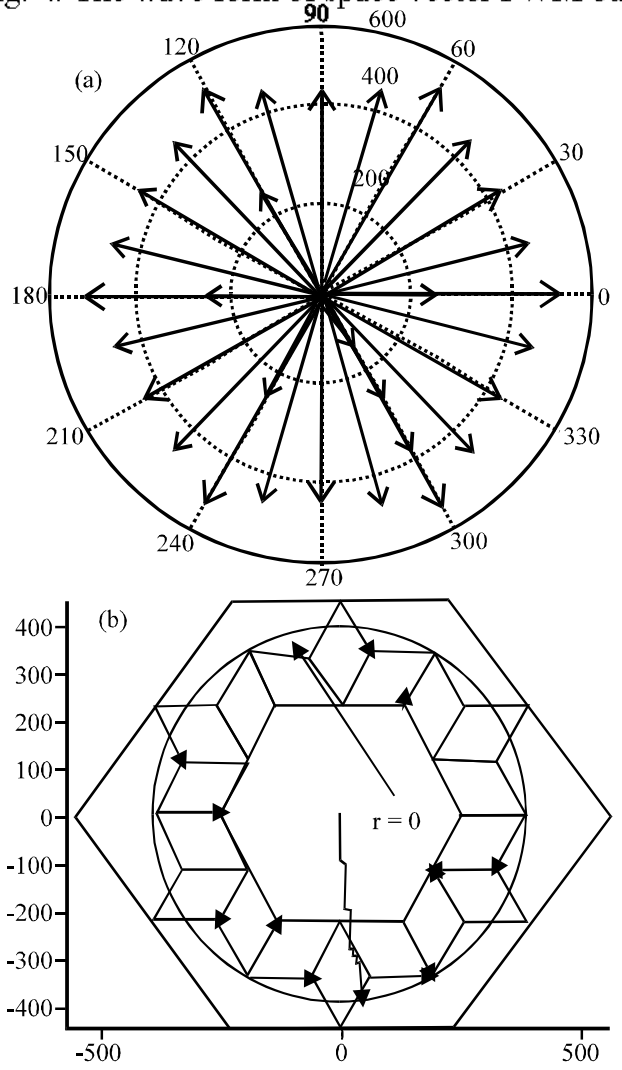

Fig. 5: Simulation results of the 5-level source inverter

Markadeh et al., 2009; Lee et al., 1994). Substituting the conditions $\Phi_{\mathrm{qr}}=0$ and $\mathrm{d} \Phi_{\mathrm{q}} / \mathrm{dt}=0$ for decoupled control and $\mathrm{d} \Phi_{\mathrm{qr}} / \mathrm{dt}=0$ for constant flux, Eq. 15 and 16 can be derived. Equation 15 indicates how the control slip command $\omega_{\mathrm{g}}{ }_{\mathrm{g}}$ can be derived in feedforward manner from the control currents $\mathrm{I}_{\mathrm{qs} 1}$ and $\mathrm{I}_{\mathrm{qs} 2}$ whereas Eq. 16 shows that rotor flux is a function of $I_{\text {ds1 }}$ and $I_{\text {dFebruary }} 15,2011 s 2$ in the steady-state condition:

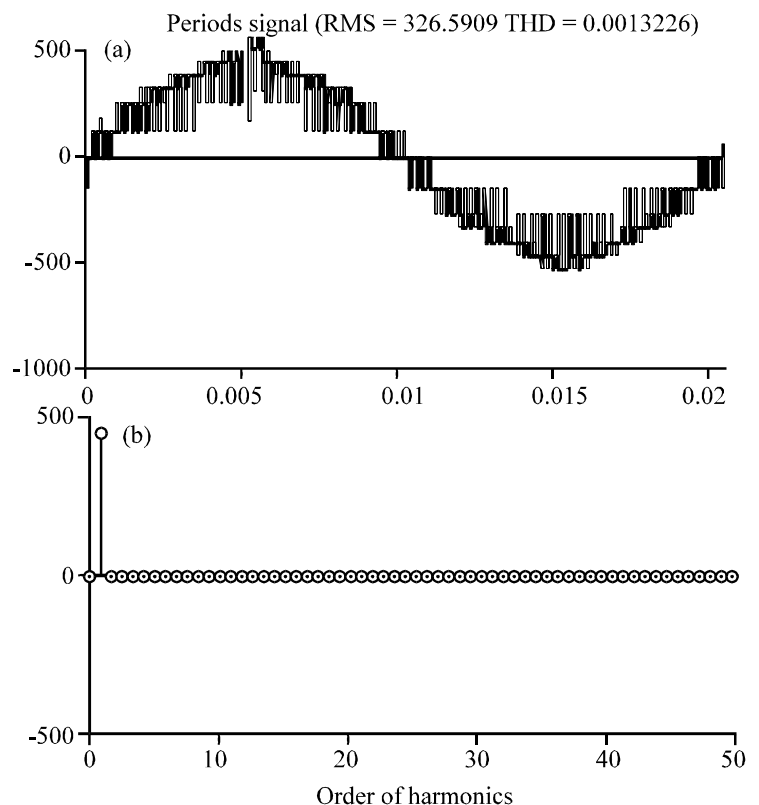

Fig. 6: Fourier analysis

$$
\begin{gathered}
\frac{\mathrm{d} \Phi_{\mathrm{dr}}^{*}}{\mathrm{dt}}+\frac{\mathrm{R}_{\mathrm{r}}}{\mathrm{L}_{\mathrm{r}}}\left(\Phi_{\mathrm{dr}}^{*}-\Phi_{\mathrm{dm}}^{*}\right)-\omega_{\mathrm{g}}^{*} \Phi_{\mathrm{qr}}^{*} \\
\frac{\mathrm{d} \Phi_{\mathrm{qr}}^{*}}{\mathrm{dt}}+\frac{\mathrm{R}_{\mathrm{r}}}{\mathrm{L}_{\mathrm{r}}}\left(\Phi_{\mathrm{qr}}^{*}-\Phi_{\mathrm{qm}}^{*}\right)-\omega_{\mathrm{g}}^{*} \Phi_{\mathrm{dr}}^{*} \\
\omega_{\mathrm{g}}^{*}=\omega_{\mathrm{r}}^{*}=\omega_{\mathrm{s}}^{*}-\omega_{\mathrm{m}}=\frac{\mathrm{R}_{\mathrm{r}}}{\mathrm{L}_{\mathrm{m}}+\mathrm{L}_{\mathrm{r}}}\left(\mathrm{I}_{\mathrm{qs} 1}^{*}+\mathrm{I}_{\mathrm{qs} 2}^{*}\right) \\
\Phi_{\mathrm{r}}=\Phi_{\mathrm{dr}}^{*}=\mathrm{L}_{\mathrm{m}}\left(\mathrm{I}_{\mathrm{ds} 1}+\mathrm{I}_{\mathrm{ds} 2}\right)
\end{gathered}
$$

Where:

$$
\omega_{\mathrm{m}}=\mathrm{p} \cdot \Omega_{\mathrm{m}}
$$

FOC needs two constant input references the torque component and the flux component by maintaining the amplitude of the rotor flux $\left(\Phi_{\mathrm{r}}\right)$ at a fixed value, we have a linear relationship between torque and flux:

$$
\mathrm{T}_{\mathrm{e}}^{*}=\mathrm{p} \frac{\mathrm{L}_{\mathrm{m}}}{\mathrm{L}_{\mathrm{m}}+\mathrm{L}_{\mathrm{r}}}\left(\mathrm{I}_{\mathrm{qs}_{1}}+\mathrm{I}_{\mathrm{qs}_{2}}\right) \cdot \Phi_{\mathrm{dr}}^{*}
$$

The relations between voltages and currents components are:

$$
\begin{aligned}
\mathrm{V}_{\mathrm{ds}_{1}}^{*} & =\mathrm{R}_{\mathrm{s}_{1}} \mathrm{I}_{\mathrm{ds}_{1}}+\mathrm{pL}_{\mathrm{s}_{1}} \mathrm{I}_{\mathrm{ds}_{1}}-\omega_{\mathrm{s}}^{*}\left(\mathrm{~L}_{\mathrm{s}_{1}} \mathrm{I}_{\mathrm{qs}_{1}}+\mathrm{T}_{\mathrm{r}} \Phi_{\mathrm{dr}}^{*} \omega_{\mathrm{g}}^{*}\right) \\
\mathrm{V}_{\mathrm{qs}_{1}}^{*} & =\mathrm{R}_{\mathrm{s}_{1}} \mathrm{I}_{\mathrm{qs}_{1}}+\mathrm{pL}_{\mathrm{s}_{1}} \mathrm{I}_{\mathrm{qs}_{1}}+\omega_{\mathrm{s}}^{*}\left(\mathrm{~L}_{\mathrm{s}_{1}} \mathrm{I}_{\mathrm{ds}_{1}}+\Phi_{\mathrm{dr}}^{*}\right) \\
\mathrm{V}_{\mathrm{ds}_{2}}^{*} & =\mathrm{R}_{\mathrm{s}_{2}} \mathrm{I}_{\mathrm{ds}_{2}}+\mathrm{pL}_{\mathrm{s}_{2}} \mathrm{I}_{\mathrm{ds}_{2}}-\omega_{\mathrm{s}}^{*}\left(\mathrm{~L}_{\mathrm{s}_{2}} \mathrm{I}_{\mathrm{qs}_{2}}+\mathrm{T}_{\mathrm{r}} \Phi_{\mathrm{dr}}^{*} \omega_{\mathrm{g}}^{*}\right) \\
\mathrm{V}_{\mathrm{qs}_{2}} & =\mathrm{R}_{\mathrm{s}_{2}} \mathrm{I}_{\mathrm{qs}_{2}}+\mathrm{pL}_{\mathrm{s}_{2}} \mathrm{I}_{\mathrm{qs}_{2}}+\omega_{\mathrm{s}}^{*}\left(\mathrm{~L}_{\mathrm{s}_{2}} \mathrm{I}_{\mathrm{ds}_{2}}+\Phi_{\mathrm{dr}}^{*}\right)
\end{aligned}
$$


For a perfect de-coupling, we will add new currents regulators, command $\mathrm{I}_{\mathrm{dgs}}^{*}$ generated by $\Phi_{\mathrm{dr}}^{*}$ (constant or programmed with speed for field-weakening control) is compared with the corresponding machine value which then generates the $\mathrm{V}_{\text {dqs }}{ }^{*}$ command after adding the decoupling compensation voltage $\mathrm{V}_{\mathrm{dqs} 1 \mathrm{c}}$ in the control loop as shown:

$$
\begin{aligned}
& \mathrm{V}_{\mathrm{ds} 1}^{*}=\mathrm{V}_{\mathrm{ds} 1}-\mathrm{V}_{\mathrm{dslc}} \\
& \mathrm{V}_{\mathrm{qs} 1}^{*}=\mathrm{V}_{\mathrm{qs} 1}+\mathrm{V}_{\mathrm{qs} \mathrm{c}} \\
& \mathrm{V}_{\mathrm{ds} 2}^{*}=\mathrm{V}_{\mathrm{ds} 2}-\mathrm{V}_{\mathrm{ds} 2} \\
& \mathrm{~V}_{\mathrm{qs} 2}^{*}=\mathrm{V}_{\mathrm{qs} 2}+\mathrm{V}_{\mathrm{qs} 2 \mathrm{c}}
\end{aligned}
$$

Where:

$$
\begin{aligned}
\mathrm{V}_{\mathrm{ds} 1 \mathrm{c}} & =\omega_{\mathrm{s}}^{*}\left(\mathrm{~L}_{\mathrm{s} 1} \mathrm{I}_{\mathrm{qs} 1}+\mathrm{T}_{\mathrm{r}} \Phi_{\mathrm{r}} \omega_{\mathrm{g}}^{*}\right) \\
\mathrm{V}_{\mathrm{qs} 1 \mathrm{c}} & =\omega_{\mathrm{s}}^{*}\left(\mathrm{~L}_{\mathrm{s} 1} \mathrm{I}_{\mathrm{d} 1}+\Phi_{\mathrm{r}}\right) \\
\mathrm{V}_{\mathrm{ds} 2 \mathrm{c}} & =\omega_{\mathrm{s}}^{*}\left(\mathrm{~L}_{\mathrm{s} 2} \mathrm{I}_{\mathrm{q} \mathbf{s} 2}+\mathrm{T}_{\mathrm{r}} \Phi_{\mathrm{r}} \omega_{\mathrm{g}}^{*}\right) \\
\mathrm{V}_{\mathrm{qs} 2 \mathrm{c}} & =\omega_{\mathrm{s}}^{*}\left(\mathrm{~L}_{\mathrm{s} 2} \mathrm{I}_{\mathrm{ds} 2}+\Phi_{\mathrm{r}}\right)
\end{aligned}
$$

In indirect vector control, the slip command signal $\omega^{*}{ }_{\mathrm{g}}$ is derived from the command $\mathrm{I}_{\mathrm{qsl}}$ through the slip gain $2 \mathrm{~L}_{\mathrm{m}} / \mathrm{T}_{\mathrm{r}}$. This signal is then added to the speed signal $\omega_{\mathrm{m}}$ and then the slip $\omega_{s}^{*}$ command is derived. In the constant torque region, the rated flux is generated by constant $I_{\text {ds }}$ command. For closed-loop flux control in both constanttorque and field-weakening regions, $I_{\text {ds }}$ can be controlled within the programmed flux control loop so that the

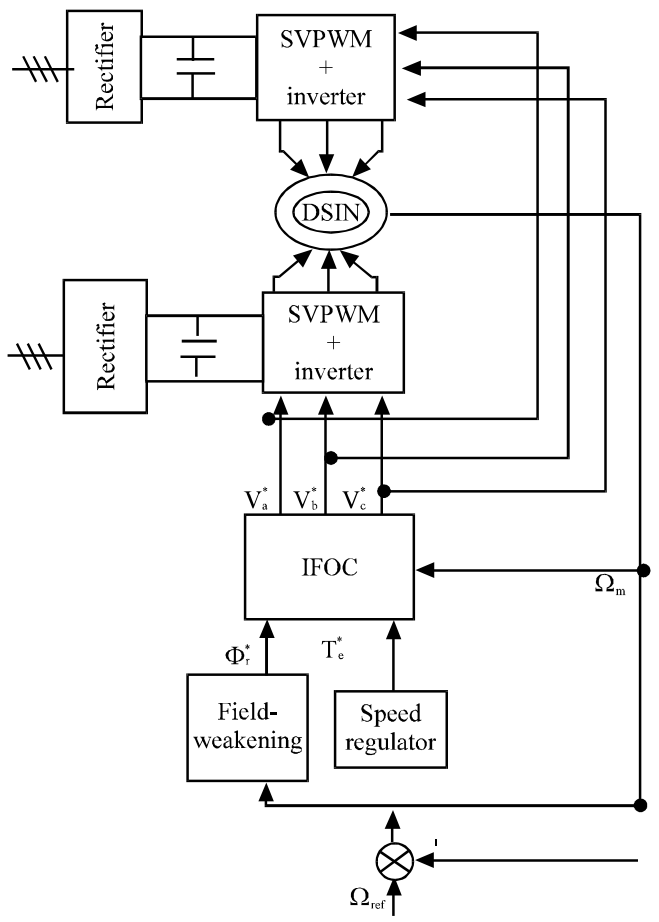

Fig. 7: Indirect field orientedcontrol of DSIM inverter always operates in SVPWM mode. The loss of flux in the field-weakening region causes some loss of torque from that of the square-wave mode but fast vector control response is retained as shown in Fig. 7.

\section{RESULTS AND DISCUSSION}

Simulation results demonstrate the effectiveness of the discussed control for DSIM with the parameters shown in Table 2, the overall block scheme is shown in Fig. 7. The decoupled torque and stator flux is achieved in the DSIM rotor flux field oriented reference frame using conventional PI regulators (Hadiouche, 2001).

The results of the speed regulation are shown in Fig. 8a-f, the corresponding speed and electromagnetic torque of motor tends to its reference command in the proposed control. The speed is linearly increased from $0-$ $2751(\mathrm{rpm})$ in $1 \mathrm{sec}$ without overtaking.

The rotor flux magnitude achieves its reference with a fast dynamics. The components of stator currents and voltages of 5-level PWM inverter are sinusoidal and in quadrature to each other. After $1.5 \mathrm{sec}$ a nominal load torque of $14[\mathrm{~N} . \mathrm{m}]$ is applied to appreciate the dynamic response of the motor.

\section{Robustness tests}

\section{We propose two tests of robustness}

Speed pursuit test: Figure 9a, b shows the simulation results of the speed reversal test, in this test the DSIM runs with positive nominal speed then the speed is reversed linearly in $2 \mathrm{sec}(\mathrm{t}$ ) (Munoz and Lipo, 2000; Gregor et al., 2008)

The amplitude of rotor flux is kept constant on 1 $[\mathrm{Wb}]$. These results verify the ability of IFOC during speed reversal. It is evident that the flux of the motor remains unaffected during the transient of the speed.

Table 2: Shown the motor parameters using in simulation

\begin{tabular}{lll}
\hline Nominal values & Values & IS-unit \\
\hline Power & 4.5 & $\mathrm{~kW}$ \\
Frequency & 50 & $\mathrm{~Hz}$ \\
Voltage $\left(\Delta \mathrm{Y}^{-1}\right)$ & $220 / 380$ & $\mathrm{~V}$ \\
Current $\left(\Delta \mathrm{Y}^{-1}\right)$ & 5.6 & $\mathrm{~A}$ \\
Speed & 2751 & $\mathrm{rpm}$ \\
Constant & Value & IS-unit \\
Poles of pair & 1 & \\
$\mathrm{Rs} 1=\mathrm{Rs} 2$ & 3.72 & $\Omega$ \\
$\mathrm{Rr}$ & 2.12 & $\Omega$ \\
$\mathrm{Ls} 1=\mathrm{Ls} 2$ & 0.022 & $\mathrm{H}$ \\
$\mathrm{Lr}$ & 0.006 & $\mathrm{H}$ \\
$\mathrm{L}_{\mathrm{rn}}$ & 0.3672 & $\mathrm{H}$ \\
$\mathrm{J}$ & 0.0625 & $\mathrm{~kg} \mathrm{~m}$ \\
$\mathrm{~K}_{\mathrm{f}}$ & 0.001 & $\mathrm{Nm}\left(\mathrm{rad} \mathrm{sec}^{-1}\right)$ \\
\hline
\end{tabular}


Int. J. Elec. Power Eng., 5 (1): 28-34, 2011
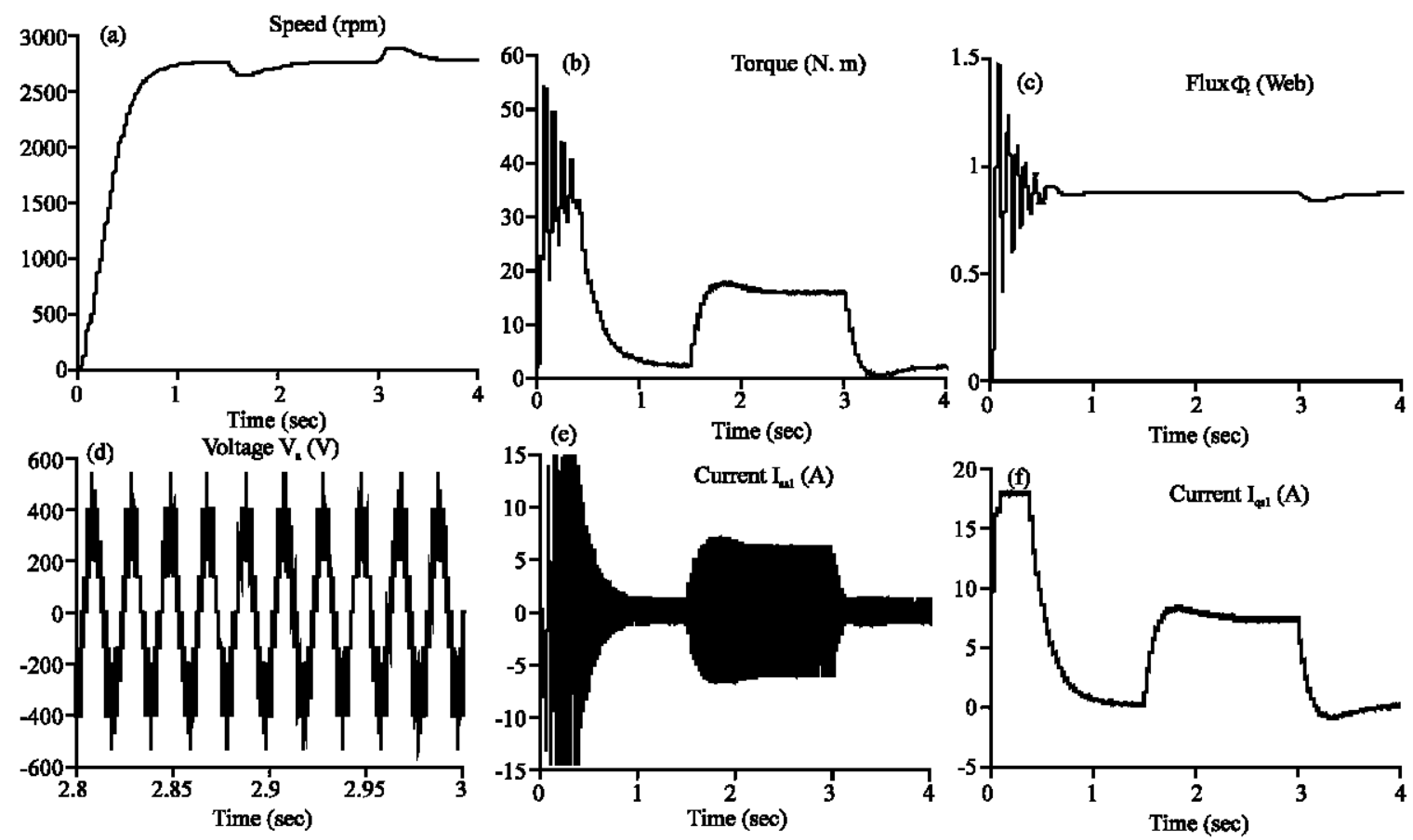

Fig. 8: Simulation results
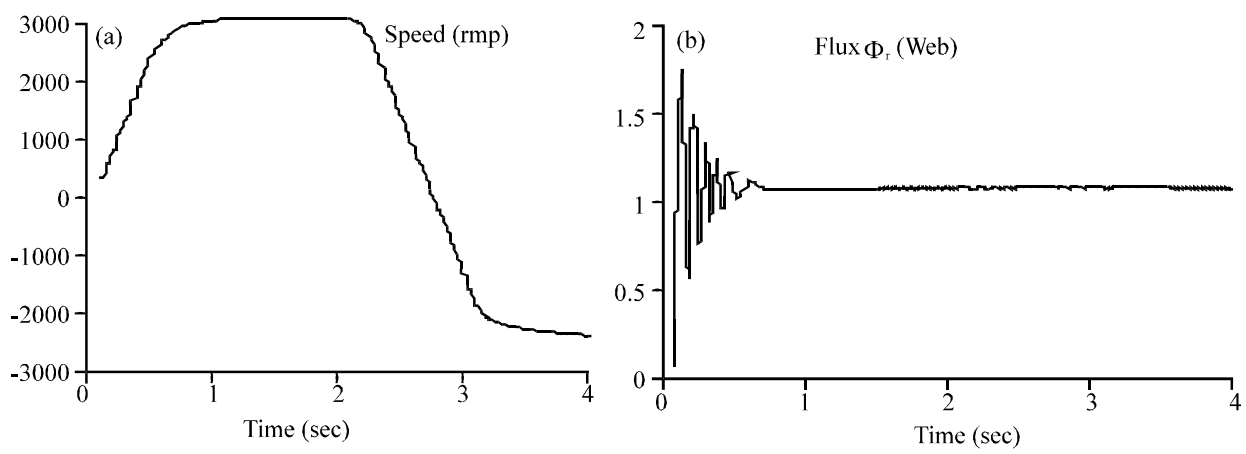

Fig. 9: Speed pursuit test results
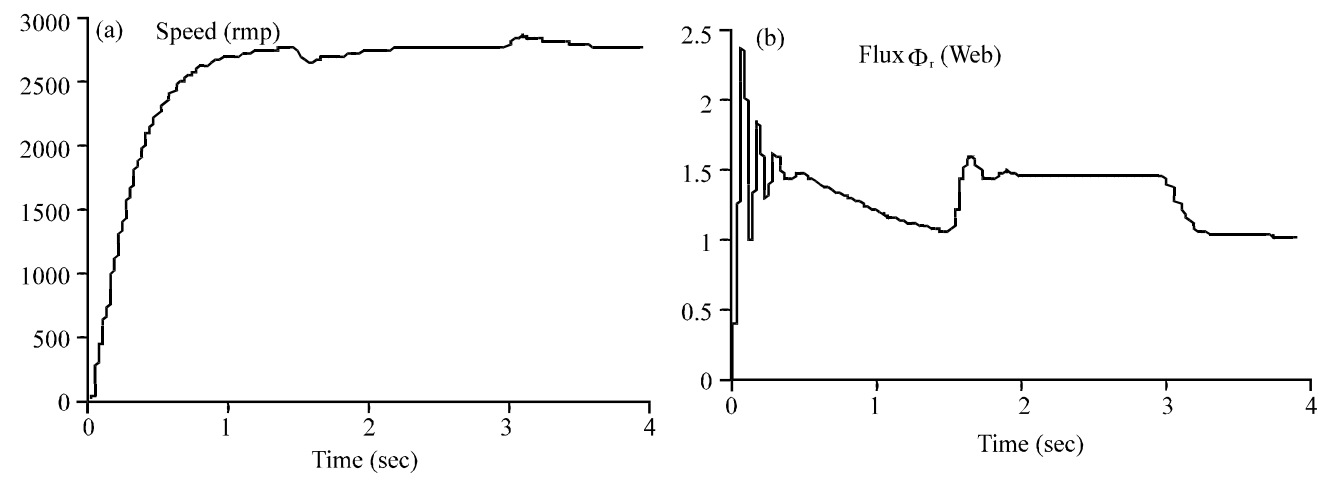

Fig. 10: Parametric variation test under $100 \%$

Parametric variation test: The Indirect Vector Control (IVC) is used widely in industry. However, one

disadvantage is that the slip gain parameters $2 \mathrm{~L}_{\mathrm{m}} / \mathrm{T}_{\mathrm{r}}$, particularly $R_{r}$, vary widely with temperature causing a 
coupling effect that deteriorates transient response and affects the flux and torque transfer characteristics (Bose, 2004). Figure 10a, b shows a parameter variation test of rotor resistance, simulation results prove clearly the effect of the slip gain on the IVC. We performed a variation of $100 \%$ of rotor resistance, we thus provide information on the performance of control in the most adverse conditions.

\section{CONCLUSION}

In this study, we introduced the rotor flux-oriented control of dual star induction motor after a general presentation of the motor model. We established the indirect rotor flux orientation where we do not need to measure or to estimate the module flux. This control method provides a good dynamic performance in closed loop. Indeed, the decoupling between the rotor flux and the electromagnetic torque is completely but the performances were only slightly damaged, this is shown by the robustness tests any time; they remain satisfactory hence, we can conclude the proposed IVC with PI regulators provide good performance.

\section{REFERENCES}

Bojoi, R., M. Lazzari, F. Profumo and A. Tenconi, 2003. Digital field-oriented control for dual three-phase induction motor drives. IEEE Trans. Ind. Appl., 39: 752-760.

Bojoi, R., A. Tenconi, F. Profumo, S. Gallardo, F. Barrero and S. Toral, 2005. A Test-rig to evaluate a dual-3phase induction motor drive. Proceedings of the 9th Spanish Portuguese Congress on Electrical Engineering, (9CHLIE) 2005.

Bose, B.K., 2004. Modern Power Electronics and AC Drive. University of Tennessee, Knoxville, Prentice Hall.
Gregor, R., F. Barrero, S. Toral and M.J. Duran, 2008. Realization of an asynchronous six-phase induction motor drive test-rig. Proceedings of the International Conference on Renewable Energy and Power Quality (ICREPQ'08) 2008.

Hadiouche, D., 2001. Contribution to the study of dual stator induction machines: Modelling, supplying and structure. Ph.D. Thesis, GREEN, Faculty of Sciences and Techniques, University Henri Poincare-Nancy, France.

Hadiouche, D., L. Baghli and A. Rezzoug, 2003. Space vector PWM techniques for dual three-phase AC machine: Analysis, performance evaluation and DSP implementation. Proceedings of the 38th IAS Annual Meeting, Oct. 12-16, France, pp: 648-655.

Lee, D.C., S.K. Sul and M.H. Park, 1994. High performance current regulator for a field-oriented controlled induction machine drive. IEEE Trans. Ind. Appli., 30: 1247-1257.

Markadeh, G.R.A., J. Soltani, N.R. Abjadi and M. Hajian, 2009. Sensorless control of a six-phase induction motors drive using FOC in stator flux reference frame. World Acad. Sci. Eng. Tech., 58: 553-559.

Menzies, R.W., P. Steimer and J.K. Steinke, 1994. Fivelevel GTO inverters for large induction motor drives. IEEE Trans. Industry Appl., 30: 938-944.

Munoz, A.R. and T.A. Lipo, 2000. Dual stator winding induction machine drive. IEEE Trans. Ind. Appl., 36: 1369-1379.

Van der Broeck, H.W., H.C. Skudelny and G.V. Stanke, 1988. Analysis and realization of a pulse width modulation based on voltage space vectors. IEEE Trans. Indus. Electr., 24: 142-150.

$\mathrm{Yu}, \mathrm{Z}$. and D. Figoli, 1998. AC induction motor control using constant $\mathrm{V} / \mathrm{H} \mathrm{z}$ principle and space vector PWM technique with TMS320C240. Application Report: PRA284A. April 1998. Texas Instruments.

Zhao, Y. and T.A. Lipo, 1995. Space vector PWM control of dual three-phase induction machine using vector space decomposition. IEEE Trans. Ind. Appl, 31: $1100-1109$. 